\title{
Cophylogenetic relationships between Anicetus parasitoids (Hymenoptera: Encyrtidae) and their scale insect hosts (Hemiptera: Coccidae)
}

\author{
Jun Deng ${ }^{1,2}$, Fang Yu' ${ }^{1}$, Hai-Bin Li ${ }^{1,2}$, Marco Gebiola ${ }^{3,4}$, Yves Desdevises ${ }^{5,6}$, San-An Wu ${ }^{2^{*}}$ and Yan-Zhou Zhang ${ }^{1^{*}}$
}

\begin{abstract}
Background: Numerous studies have investigated cospeciation between parasites and their hosts, but there have been few studies concerning parasitoids and insect hosts. The high diversity and host specialization observed in Anicetus species suggest that speciation and adaptive radiation might take place with species diversification in scale insect hosts. Here we examined the evolutionary history of the association between Anicetus species and their scale insect hosts via distance-based and tree-based methods.
\end{abstract}

Results: A total of 94 Anicetus individuals (nine parasitoid species) and 113 scale insect individuals (seven host species) from 14 provinces in China were collected in the present study. DNA sequence data from a mitochondrial gene (COI) and a nuclear ribosomal gene (28S D2 region) were used to reconstruct the phylogenies of Anicetus species and their hosts. The distance-based analysis showed a significant fit between Anicetus species and their hosts, but tree-based analyses suggested that this significant signal could be observed only when the cost of host-switching was high, indicating the presence of parasite sorting on related host species.

Conclusions: This study, based on extensive rearing of parasitoids and species identification, provides strong evidence for a prevalence of sorting events and high host specificity in the genus Anicetus, offering insights into the diversification process of Anicetus species parasitizing scale insects.

Keywords: Host-parasitoid interactions, Sorting, Speciation, COI, 28S-D2

\section{Background}

The study of the evolution of host-parasite associations has a long history, with the first paper published a century ago [1-6]. Since then, numerous host-symbiont systems have been observed and several analytical methods proposed. When the host and parasite phylogenetic trees are the same, that is when visual inspection show that the two trees precisely match, with hosts and corresponding parasites at the same positions, a cospeciation pattern can be directly inferred. In other situations, the reconstruction of a hypothetical coevolutionary scenario is not straightforward, as it can involve different events including cospeciation, duplication, lineage sorting and

\footnotetext{
*Correspondence: sananwu@bjfu.edu.cn; zhangyz@ioz.ac.cn

${ }^{2}$ Key Laboratory for Silviculture and Conservation of Ministry of Education,

Beijing Forestry University, Beijing 100083, China

'Key Laboratory of Zoological Systematics and Evolution, Institute of

Zoology, Chinese Academy of Sciences, Beijing 100101, China

Full list of author information is available at the end of the article
}

host-switching [7]. In such cases, a rigorous and specific method must be used to differentiate cospeciation from a number of potential scenarios.

In the last two decades, several methods were developed to assess the level of cospeciation in symbiotic associations [8], and the availability of programs such as TreeMap [9], TreeFitter [10,11] and ParaFit [12] has led to an increased level of accuracy in host-parasite cospeciation studies [13-15]. These software search for an optimal evolutionary scenario for the association between hosts and their symbionts (for example, parasites). Previous work has investigated cospeciation between parasites and their hosts, such as lice and mammals [16-21], plants and insects [22-25], plants and fungi [26], fish and Platyhelminthes $[7,27,28]$, and animals and viruses $[29,30]$. However, cophylogeny between parasitoids and their insect hosts has been rarely investigated, with the few previous studies focusing on Lepidoptera-parasitoids systems $[31,32]$. 
Almost every plant-feeding insect species is attacked by at least one parasitoid species [33] and even without strict host specificity, there are at least as many (and possibly more) parasites than free-living species. Among Hymenopteran parasitoids, Encyrtidae (Hymenoptera: Chalcidoidea) is an economically important group of nearly 4000 species of natural enemies of Lepidoptera, scale insects and other insect orders [34]. The genus Anicetus Howard is well known for its important economic significance. Several Anicetus species, such as $A$. beneficus Ishii \& Yasumatsu, are frequently used as biological control agents of wax and soft scales of the genus Ceroplastes Gray (Homoptera: Coccidae), which are significant pests of important agricultural crops [35-37]. However, due to their small size and frequent lack of distinct morphological characters, the accurate identification of wax scales and parasitoids is still a great challenge for taxonomists. The study of cophylogenetic patterns between species of Anicetus and Ceroplastes is therefore difficult, however, it is also crucial for a better understanding of speciation and diversification processes in this parasitoid genus. Two recent DNA barcoding studies of Anicetus and their wax scale hosts were used as a taxonomic reference for the present study $[38,39]$.

Several recent DNA-based studies strongly suggest that morphologically similar lineages traditionally considered as single species are instead genetically isolated, and in many cases host-specific [40-43]. Koinobiont parasitic Hymenoptera, in particular, display an intricate physiological relationship with their hosts and consequently tend to have relatively narrow host ranges [44]. The degree of host specificity of Encyrtidae is variable. For example, Anagyrus sp. nov. nr. sinope and Leptomastix dactylopii Howard are two parasitoids of mealybug species; the former is highly host specific, whereas the latter displays a wider host range, having been recorded from more than 20 host species [45]. Some Encyrtidae species such as Copidosoma floridanum (Ashmead) [46] exclusively parasitize a given host family or subfamily, while other Copidosoma species have a wider host range and attack different families of Lepidoptera [47]. High host specificity has been reported in Comperia merceti (Compere) [48], Gyranusoidea tebygi Noyes [49,50], and more recently in Encyrtus sasakii [51]. Zhang et al. [38] recently showed that host specificity tends to be strict in the Anicetus group, where species are usually restricted to one host species. Furthermore, Anicetus species have a low mobility and individuals that leave the host die within a few hours or days, hence they are totally reliant upon their hosts for survival. This makes the genus Anicetus a good candidate for evolution via cospeciation with their insect hosts.

The nine Anicetus species used for this study exhibit narrow host ranges and only parasitize wax scales. A large number of Ceroplastes individuals were collected throughout China (see Materials and methods). The aims of this study were to reconstruct molecular phylogenies for wax scale insects and their Anicetus parasitoids, and to assess the degree of cospeciation in this host-parasitoid association in order to better understand the drivers of species diversification in this group of parasitoids.

\section{Results \\ Phylogenetic analyses}

The partition homogeneity test indicated that the COI and $28 \mathrm{~S}$ datasets did not display any significant signal of heterogeneity $(\mathrm{P}=0.35$ for host dataset and $\mathrm{P}=0.66$ for parasitoids dataset). This test compared the summed lengths of most-parsimonious trees computed from each dataset (i.e. gene) to the lengths of trees generated from random partitions of the combined sequences of both genes [52], and calculated the probability of obtaining a random tree similar or shorter to the length of observed summed tree. The two datasets were then combined for subsequent phylogenetic analysis. In the host tree, Parasaissetia sp. was strongly supported as basal clade and Pulvinaria aurantii was sister group to the clade of all Ceroplastes species, which was strongly supported (Figure 1). For parasitoids, most Anicetus species were strongly supported except for two groups of $A$. benificus and $A$. rubensi individuals $(\mathrm{PP}=0.58)$ (Figure 2). These two species are morphologically very similar, reflecting the taxonomic uncertainty at this level.

The parasite and host phylogenies built from consensus sequences were used to assess their phylogenetic congruence (Figure 3). These trees, using consensus sequences, were identical to previous phylogenies (Figure 1, Figure 2). Furthermore, not all parasitoids from the same host clustered in the same clade, for example, A. dodonia Ferrière and $A$. aligarhensis Hayat, Alam \& Agarval clustered together even though they use different hosts.

\section{Topology-based analyses: Treemap $3.0 \beta$ and Jane 4}

The tanglegram built from the phylogenetic trees and individual associations between Anicetus species and their scale insect hosts (Figure 3) suggested that the trees did not perfectly match. We then used Treemap $3.0 \beta$ that generated 64 optimal solutions to reconcile the two trees with the lowest number of coevolutionary events considering their costs (Figure 4), none of which indicated significant congruence. We used different cost sets for each of these coevolutionary events to produce different results in Jane 4 (Table 1). In both methods, each event is given a cost inversely related to the likelihood of that event [53], and a global cost is computed by summing the costs of all events needed to fit the parasitoid tree onto the host tree (i.e. tree reconciliation). A significant 


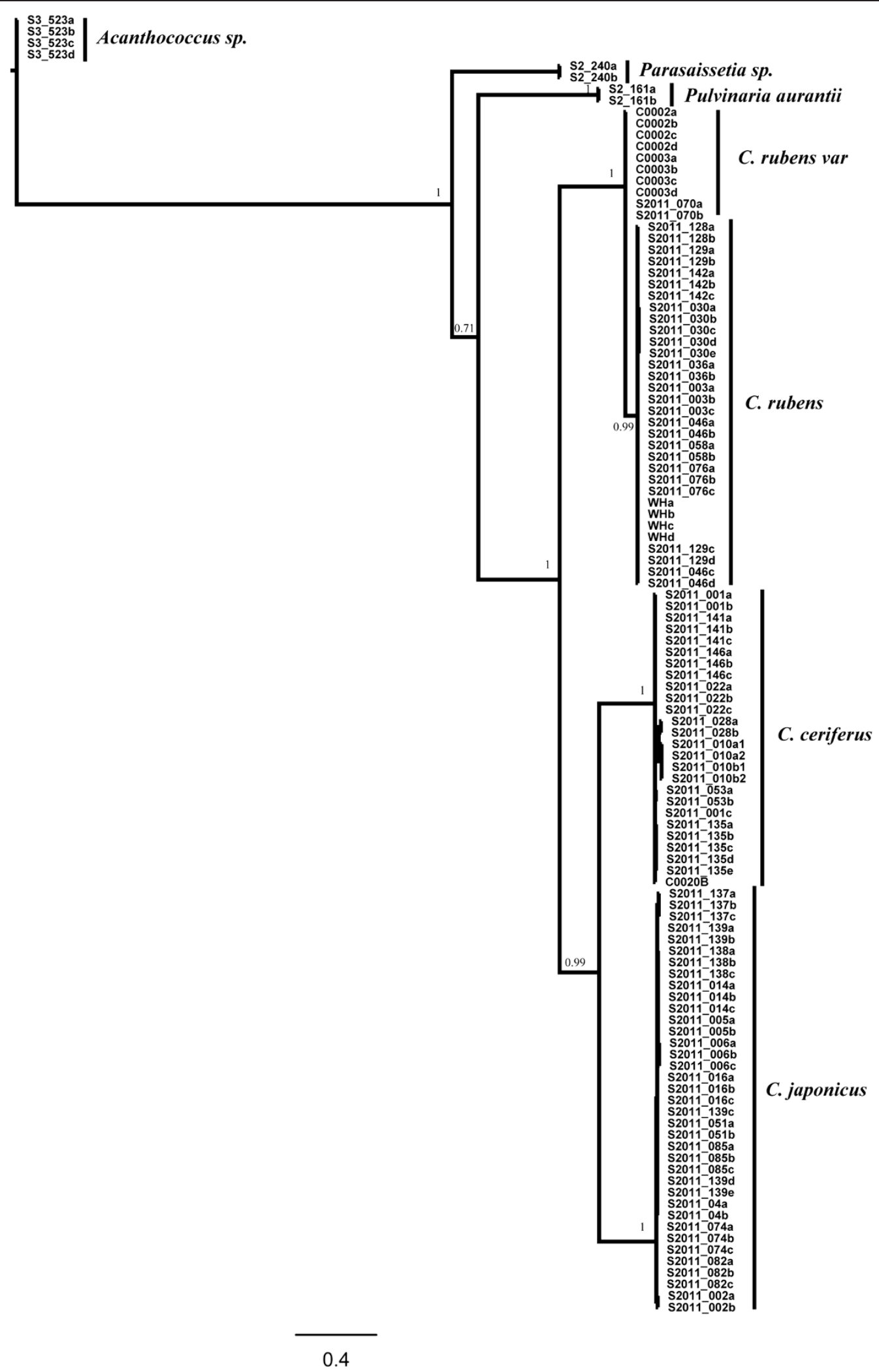

Figure 1 Bayesian trees of scale insect species based on combined COI and $28 \mathrm{~S}$ data. Support values (posterior probabilities) are provided for each node. 


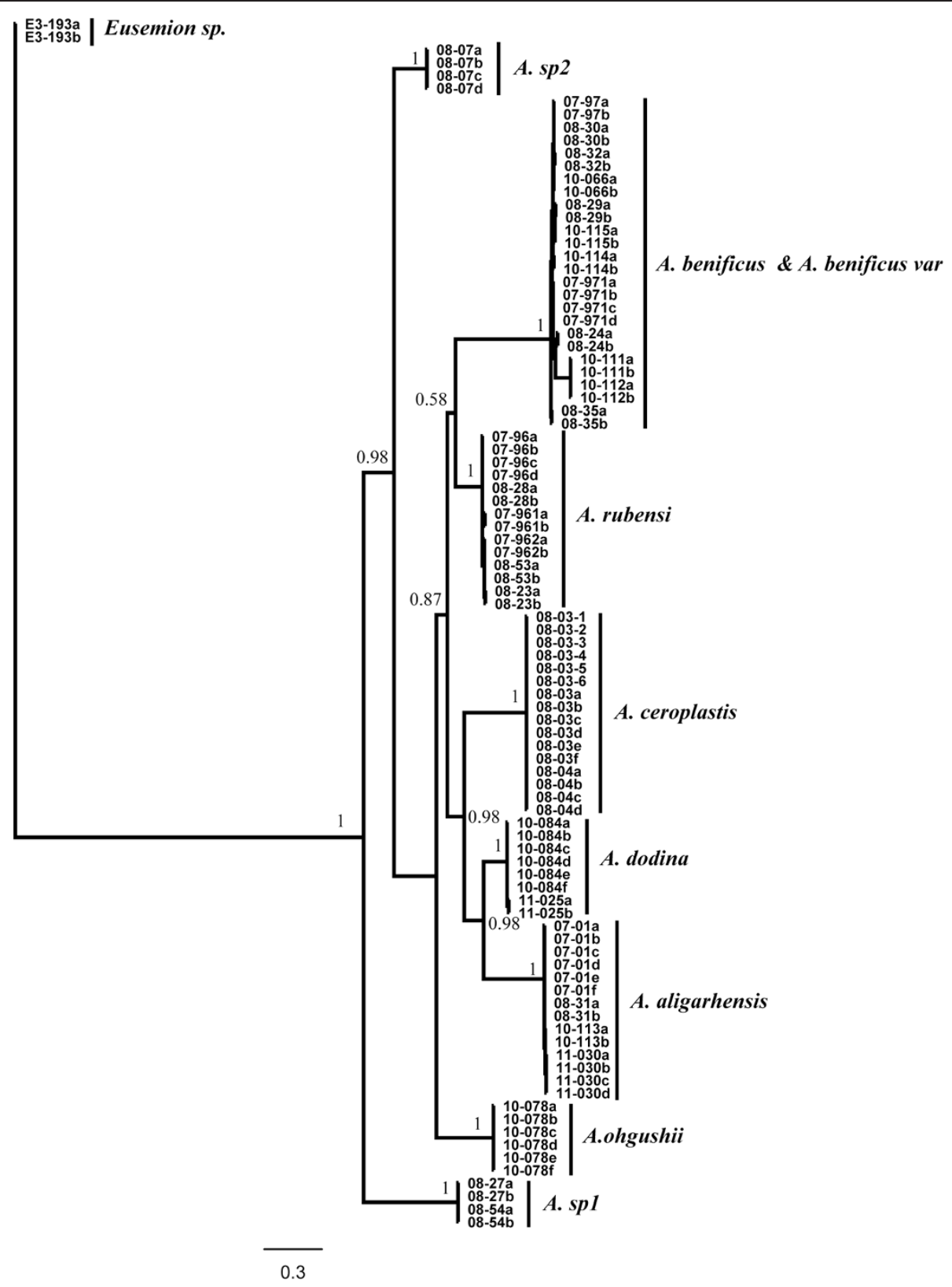

Figure 2 Bayesian trees of Anicetus species based on combined COI and $\mathbf{2 8 S}$ data. Support values (posterior probabilities) are provided for each node.

global cost $(\mathrm{P}=0.004)$ was only observed in Jane with the TreeFitter default cost model, that is 5 for cospeciation, 4 for duplication, 0 for host-switch, 7 for loss and 0 for failure to diverge. Setting the costs of host-switch to high values in the TreeFitter default model caused the overall fit to become significant, suggesting that hostswitch is rare in this host-parasitoid system. Meanwhile, a large number of sorting events (7) were found with the TreeFitter default model, in contrast to $0-1$ sorting events with the other models. In addition, we compared the patristic distances (phylogenetic divergence) between parasitoid and hosts in copaths using TreeMap (Figure 5), to assess whether branch lengths are correlated in cospeciating hosts and parasitoids (corresponding branches in the two trees are called "copaths"). A strong positive correlation would support cospeciation, and in this case the slope of the linear relationship indicated the relative evolutionary rates in hosts and parasitoids because the same genes were used to build the phylogenies. The branch length randomization test suggested a strong significant correlation between copaths $(r=0.8145)$, supporting the hypothesis that cospeciation has occurred in this host- 


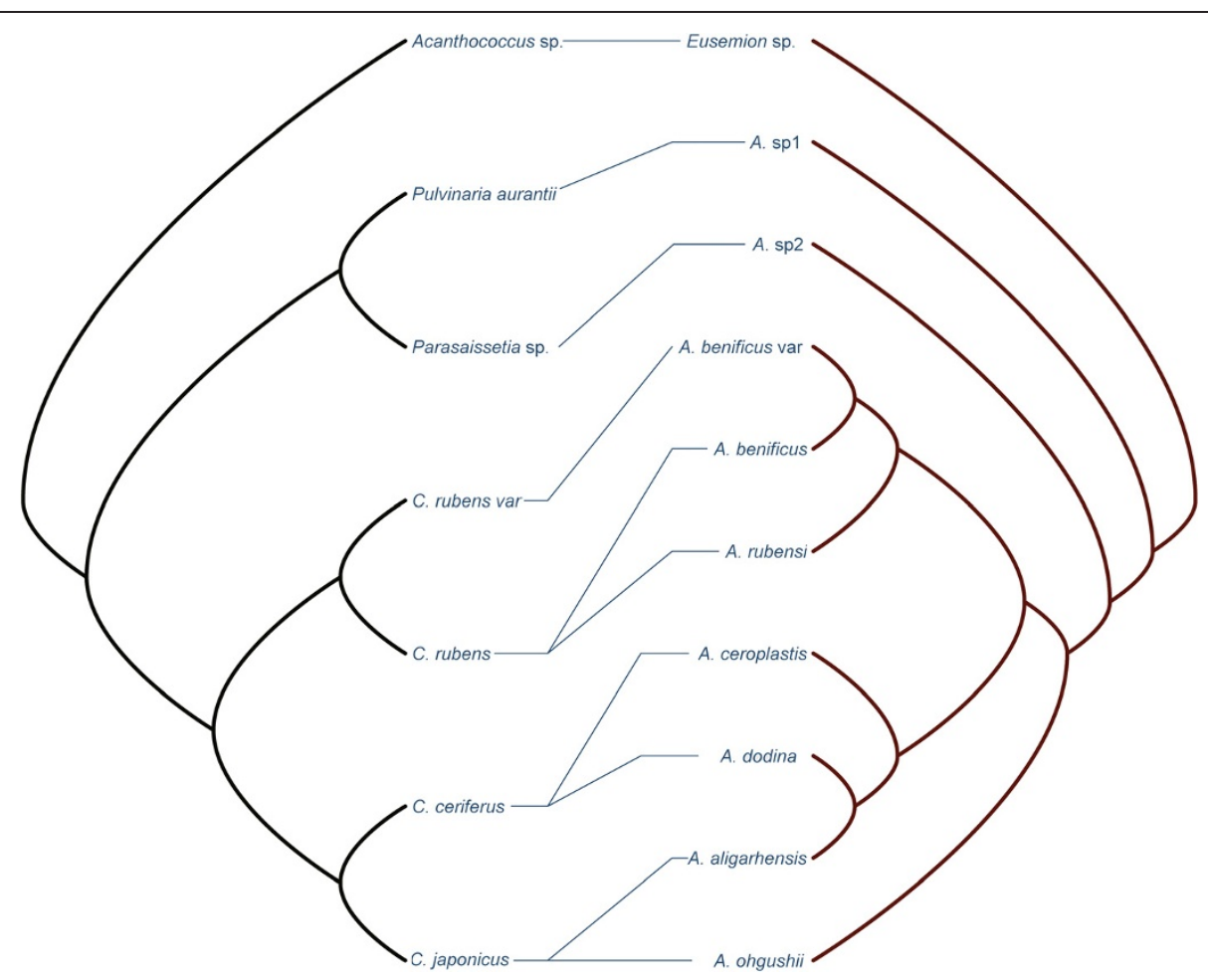

Figure 3 Tanglegram between parasite (right) and host phylogenies (left) reconstructed from COI and 28S data. Lines connecting scale insects and parasitoids indicate the pattern of host specificity.

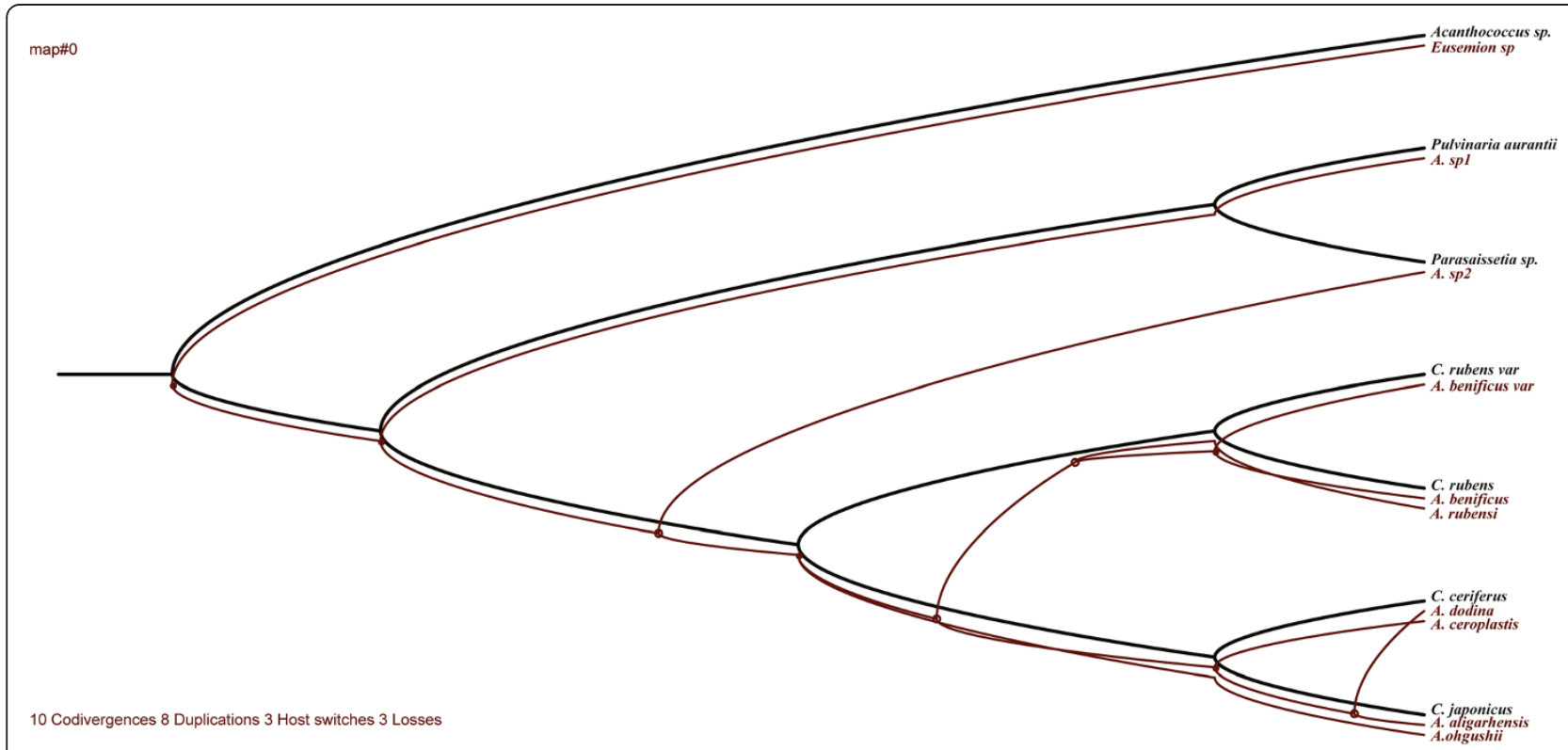

Figure 4 One of the 64 optimal cophylogenetic scenarios between the Anicetus tree and their hosts' tree from TreeMap 3.0 (10 codivergences, 8 switches, 3 duplications, 3 losses, total cost $=7$ ). Black and red lines represent hosts and their parasitoids, respectively. 
Table 1 Results of cophylogenetic analyses with Jane for Anicetus and their hosts

\begin{tabular}{|c|c|c|c|c|c|c|c|c|}
\hline Model & $\begin{array}{l}\text { Event } \\
\text { costs }\end{array}$ & $\begin{array}{c}\text { Total } \\
\text { cost }\end{array}$ & Cospeciation & Duplication & $\begin{array}{c}\text { Host } \\
\text { switch }\end{array}$ & $\begin{array}{c}\begin{array}{c}\text { Sorting } \\
\text { event }\end{array} \\
\end{array}$ & $\begin{array}{c}\text { Failure } \\
\text { to diverge }\end{array}$ & P-value \\
\hline Jane default model & 01211 & 10 & 4 & 1 & 4 & 1 & 0 & 0.22 \\
\hline TreeMap default model & 01111 & 6 & 3 & 1 & 5 & 0 & 0 & 0.53 \\
\hline TreeFitter default model & 00211 & 7 & 5 & 4 & 0 & 7 & 0 & $0.004^{*}$ \\
\hline Host switch-adjusted TreeFitter model & 00111 & 5 & 2 & 2 & 5 & 0 & 0 & 0.13 \\
\hline Codivergence adjusted TreeFitter model & 10111 & 7 & 0 & 2 & 7 & 0 & 0 & 0.56 \\
\hline Equalweights & 11111 & 9 & 0 & 0 & 9 & 0 & 0 & 1 \\
\hline
\end{tabular}

Asterisks indicate significance at the $1 \%$ level. Columns indicate the number of each event type necessary to reconcile host and parasite trees under different event cost schemes. Event costs are for cospeciation, duplication, host switching, sorting event, and failure to diverge, respectively. P-values were computed from 999 random reconstructions.

parasitoid association. The slope of the linear relationship using the reduced major axis method was 3.6, suggesting that Anicetus species have evolved more rapidly than their scale insect hosts. This result is consistent with previous results obtained for Achrysocharoides (Hymenoptera: Eulophidae) [32].

\section{Distance-based analysis: ParaFit}

We used ParaFit to compare patristic distance between hosts and their corresponding parasitoids, to test the global fit between the two trees. In addition the method assesses if each individual host-parasitoid association (link) significantly contributes to the global fit, to evaluate which ones have a structuring effect. The global test indicated a significant congruence between Anicetus and scale insect trees $(\mathrm{P}=0.01602)$. However, the test of individual links showed that not all host-parasite associations significantly contributed to this global fit: 4 out of 10 individual links were significant (Eusemion sp.-Acanthococcus sp., A. ohgushii-C. japonicus, A dodina-C. ceriferus and $A$. aligarhensis-C. japonicus), suggesting their structuring role in the global congruence.

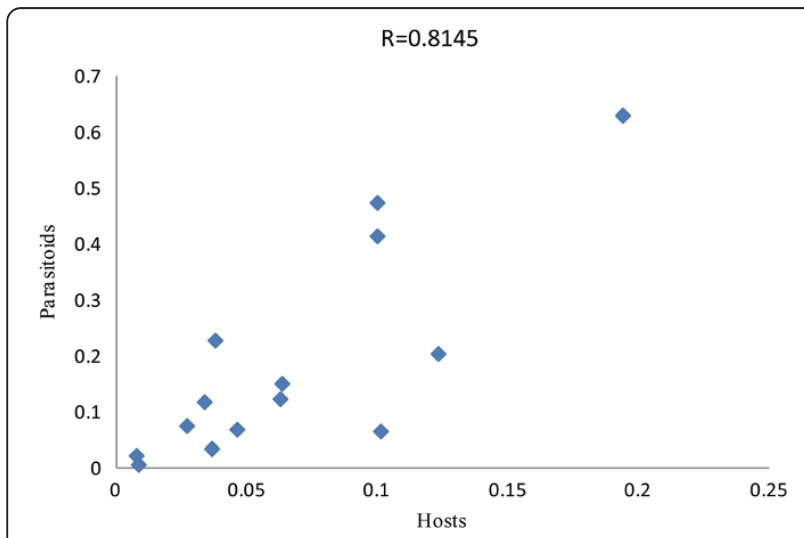

Figure 5 Relationship between patristic distances of copaths for Anicetus species and their scale insect hosts.

\section{Discussion}

A cophylogenetic signal is weak or absent in most hostparasite associations that have been studied to date [54-56]. However, significant cospeciation has been inferred in systems where host-switching is prevented by the asocial lifestyle of the host and the low mobility of the parasite. Examples include rodent-lice associations $[6,18]$ and insect-symbiont systems where bacteria, needed for reproduction, are transmitted maternally $[57,58]$. The present study can be added to these few examples of extensive cospeciation, supported using various methods.

This study is the first to thoroughly investigate the cophylogenetic interactions between Anicetus and their scale insect hosts, and suggests the ubiquity of sorting events coupled with strong host specificity in the genus Anicetus. Nine genetically distinct species were clearly delineated in the phylogenic tree based on combined molecular data (28S-D2 and COI). Anicetus benificus, A. benificus_var and $A$. rubensi, all parasitoids of C. rubens, were found grouped in the phylogeny, which is congruent with the current taxonomy (Figure 2). Furthermore, morphological data confirmed this pattern, for example, the antennal clava and ovipositor of these three species are similar to each other [59]. However, not all Anicetus species from the same host were found to cluster in the phylogenetic tree: A. aligarhensis and A. dodonia, from two different hosts, appeared to cluster together as sister species with a high posterior probability value. The presence of host-switching (one daughter parasitoid lineage shifting to a distant host) or sorting events (when the parasitoid is absent, for example, has become extinct, in one of the daughter host lineages) may explain this result.

The distance-based analysis showed a strong cophylogenetic signal between Anicetus species and their scale insect hosts. However, tree-based analyses suggested that this signal is significant only when the cost of hostswitching is high. In addition, a sharp increase in the number of sorting events was found using the TreeFitter cost model, suggesting that sorting has been an important 
component of Anicetus diversification. Paterson et al. [14] have suggested that three processes can lead to the absence of parasites from their hosts: sampling error, parasite extinction and the patchy distribution of parasites (resulting in the so-called "missing the boat" process). We believe that our sampling was dense enough to strongly reduce, if not eliminate, sampling error. Our observations suggest that parasitism rates even within one species are not stable and low rates are often found in some locations. Chantos et al. [60] observed that the encyrtid wasp Neodusmetia sangwani (Subba Rao) exhibits a patchy geographic distribution. Our investigations showed that most Ceroplastes species only carried up to three Anicetus individuals and that a patchy distribution of Anicetus species may be very common in wax scales. Therefore, Anicetus species may have been absent from the host founder population because of a patchy distribution and the small size of the host population when speciation took place, leading to a sorting event via a "missing the boat" process. In addition, host specific parasites are likely to possess fewer populations than multi-host parasites [56]. These observations support the conclusion that some parasites in this study may have gone extinct from a host lineage after a host speciation event.

In the present study, we observed that Anicetus species only attacked and parasitized single host species. This is coherent with the hypothesis that the evolution of obligate parasites (or parasitoids) with limited ability to transfer between different host species is tightly linked to the evolution of their own host species [61]. However, the congruence of host-parasite phylogenies is not perfect, which can be explained by a mix of coevolutionary events such as host switching, parasite speciation without host speciation (duplication), parasite extinction, and non-colonization of all host lineages [62]. A previous study suggested that Anicetus species is adapted to narrow niches or restricted to particular hosts. Specifically, A. ceroplastis, A. beneficus, A. rubensi and A. aligarhensis develop on the same host (Ceroplastes spp.), and thus far they have not been reared from other hosts across China [38]. After investigating a high number of samples from different provinces, we found that these species and others display strict host specificity (Table 2). For example, $A . \mathrm{sp} 1$ and $A$. sp2 were observed to only attack Pulvinaria aurantii and Parasaissetia sp., respectively. This host specificity is not congruent with former multi-host records of the genus Anicetus observed in previous studies [63-65], which could be explained by the extensive examination carried out in the present study, coupled with the use of molecular data.

Many studies have supported the hypothesis that koinobionts are more host-specific than idiobionts [66-68], and a high degree of host specificity is relatively common among parasitic Hymenoptera [43,51,69]. Traditional
Table 2 A detailed description of host specificity of each Anicetus species

\begin{tabular}{cccc}
\hline Anicetus species & Location & Host & Date \\
\hline Eusemion sp. & Guangxi, baise & Acanthococcus sp. & 2.vi.2013 \\
A. sp2 & Fujian, Nanjing & Parasaissetia sp. & 23.ix.2008 \\
A. sp1 & Shanghai & pulvinaria aurantii & 19.v.2008 \\
A. aligarhensis & Shanxi, Taiyuan & C. japonicus & 3.vi.2007 \\
A. aligarhensis & Hubei, Jingzhou & C. japonicus & 10.v.2011 \\
A. aligarhensis & Hubei, Xiangyang & C. japonicus & 15.viii.2011 \\
A. ohgushii & Zhejiang, Yuyao & C. japonicus & 29.xii.2010 \\
A. dodonia & Anhui, Wuhu & C. ceriferus & 8.vi.2010 \\
A. ceroplastis & Beijing & C. ceriferus & 15.ix.2008 \\
A. rubensi & Shanghai & C. rubens & 11.v.2008 \\
A. rubensi & Jiangxi, Yichun & C. rubens & 13.v.2009 \\
A. rubensi & Jiangxi, Xinyu & C. rubens & 15.xi.2008 \\
A. rubensi & Hunan, Changsha & C. rubens & 11.xi.2006 \\
A. beneficus & Shanghai & C. rubens & 11.v.2008 \\
A. beneficus & Jiangxi, Yichun & C. rubens & 13.xi.2008 \\
A. beneficus & Hangzhou & C. rubens & 24.ix.2009 \\
A. beneficus & Sichuan, Chengdu & C. rubens & 16.v.2009 \\
A. beneficus & Austrailia & C.rubens & 15.xi.2010 \\
A. beneficus & Hangzhou & C. rubens & 24.xi.2008 \\
A. beneficus & Anhui, HeFei & C. rubens & 20.v.2011 \\
A. beneficus & Jiangxi, Xinyu & C. rubens & 20.xi.2009 \\
A. beneficus & Jiangsu, Nanjing & C. rubens & 9.x.2009 \\
A. beneficus var & Yunnan, Kunming & C.rubens & 26.iv.2011 \\
\hline & & & \\
& & &
\end{tabular}

species of parasitoid wasps that use many different hosts for their larvae can be complexes of cryptic taxa, each of them adapted to use only a few hosts [69]. An increasing number of studies using molecular data suggest that species traditionally considered generalists are in fact complexes of cryptic taxa, each of them adapted to narrow niches $[38,40,42,70]$. To avoid such problematic species identification leading to biased patterns of host specificity, taxonomic issues such as careful species discrimination and recognition of cryptic taxa must be carefully addressed before conducting cophylogenetic studies.

\section{Conclusions}

In this study, we carefully assessed the identity of Anicetus species parasitizing wax scales and verified the taxonomic status of their hosts using laboratory rearing. Through the distance-based analysis (ParaFit) and the topology-based analyses (TreeMap 3.0 $\beta$ And Jane 4), we presented strong evidence for a prevalence of sorting events and high host specificity in the genus Anicetus, offering insights into the diversification process of Anicetus species parasitizing scale insects. Our study emphasizes that extensive rearing of parasitoids and accurate identification are important for 
investigating coevolutionary relationships in host-parasitoid associations.

\section{Methods \\ Sampling}

All species of Anicetus were reared from adults or latestage nymphs of wax scale insects (Ceroplastes spp.) collected in the field from 14 provinces in China. Different Ceroplastes species present on the same twig or leaf were isolated and kept individually in glass vials for at least 2 months to allow parasitoids to emerge. The collected parasitoids were stored in 95\% ethanol for taxonomic identification and molecular study. Parasitoids were identified by author ZYZ and Ceroplastes hosts by author SAW. In total, we collected seven out of twelve Anicetus species known from China [34] and two other species tentatively named as Anicetus sp1 (reared form Pulvinaria aurantii) and Anicetus sp2 (reared from Parasaissetia sp.). Although we have collected six out of ten Ceroplastes species known in China [39], Anicetus species were reared from three of them (see Additional file 1 and Additional file 2). Voucher specimens were deposited at the Institute of Zoology, Chinese Academy of Sciences, Beijing.

\section{DNA extraction, amplification and sequencing}

Total DNA was extracted from individuals preserved in 95\% ethanol using DNeasy Blood \& Tissue Kit (Qiagen), following the manufacturer's protocol. Protocols for PCR amplification of COI and 28S followed Zhang et al. [38] for parasitoids and Deng et al. [39] for scale insects. Products were visualized on $1 \%$ agarose and the most intense products were sequenced bidirectionally using BigDye v3.1 on an ABI3730xl DNA Analyzer (Applied Biosystems). GenBank accession numbers are given in Additional file 1 and Additional file 2.

\section{Phylogenetic reconstruction}

Sequences of COI and 28S were aligned using Clustal W 1.8.3 [71] as implemented in BioEdit 7.0.5 [72]. Some sequences of hosts and parasitoids were retrieved from previous studies [38,39]. Several samples collected from other cities in China (see electronic supplementary material, Additional file 1 and Additional file 2) were added to our data. A total of 94 Anicetus individuals (nine parasitoid species) and 113 scale insect individuals (seven host species) were used in the present study. To confirm that sequence data could be concatenated, the homogeneity of the COI and $28 \mathrm{~S}$ data sets was assessed using a partition homogeneity test (100 replicates) [73] as implemented in the program PAUP* 4.0b10 [74]. We estimated the DNA sequence evolution model that best fit the data using jModelTest 0.1.1. [75], applying the Akaike Information Criterion (AIC). For the COI data, we used a codon model (nucmodel $=$ codon, code $=$ metmt in MrBayes, see below). For the $28 \mathrm{~S}$ data, the selected models for hosts and parasitoids were $\mathrm{HKY}+\mathrm{G}$ and GTR + G, respectively. Bayesian analyses (BA) of combined data sets were performed with MrBayes 3.2 [76] with these evolutionary models assigned separately to the respective partitions. A Markov chain Monte Carlo search was run with four chains of 10,000,000 generations sampled once every 100 generations. A plot of number of generations versus the log probability was used to check for stationarity, and posterior probability values (PP) were calculated after the first $25 \%$ of trees were discarded. To test the convergence of chains and assess stationarity of BA parameter values, the effective sample sizes (ESS) of all parameters were calculated using Tracer 1.5 [77]. Analyses of these parameters in Tracer 1.5 shown that most ESS values were exceeding 500 , indicating strong equilibrium after discarding burn-in. Eusemion sp. (Hymenoptera: Encyrtidae) was chosen as an outgroup of Anicetus parastoids and Acanthococcus sp. (Hemiptera: Eriococcidae) as an outgroup of coccids.

\section{Cophylogenetic analyses}

Seven host species and nine Anicetus species were used for cophylogenetic analyses. Consensus sequences of COI and $28 \mathrm{~S}$ were created by collapsing all sequences from the same species using BioEdit 7.0.5, and used in the analysis of the congruence of parasite and host phylogenies. Several methods using TreeMap [9,78], TreeFitter [11], Jane 4 [79] and ParaFit [12], are available to study the congruence between symbiont and host phylogenies. In the present study, three methods were used: a distance-based method called ParaFit implemented in CopyCat [80] and topology (or tree)-based methods implemented in Jane 4 and TreeMap 3 (developed by Mike Charleston and available at http://sites.google.com/site/cophylogeny).

TreeMap is a popular topology-based program that reconciles two trees using four types of events (cospeciation $(\mathrm{C})$, host-switching $(\mathrm{H})$, duplication $(\mathrm{D})$, and sorting (S)) to graphically depict the differences between the phylogenies $[9,81]$. In our study, TreeMap $3.0 \beta$ was used to reconstruct the tanglegram and assess the congruence between parasite and host phylogenies (including outgroups). We also computed the correlation between evolutionary divergences in previously identified cospeciating pairs ("copaths") in TreeMap to test whether parasitoids evolve faster than their hosts [9]. As the same genes were used to build host and parasite trees, the slope of the linear relationship between corresponding divergences reflect their relative evolutionary rates.

Jane 4 uses a polynomial time dynamic programming algorithm in conjunction with a genetic algorithm to compare the two tree topologies by optimally mapping the parasite tree onto the host tree using different event 
costs to find very good, and often optimal, solutions to reconcile the two phylogenetic trees $[79,82]$. We used Jane 4 with 100 generations and a population size of 200 as parameters of the genetic algorithm. Six different cost models were used to find the minimum total cost (see Table 1). All models were tested using random tip mappings with 100 randomizations. Jane 4 can handle polytomies, considered as soft polytomies, which are resolved in order to minimize the global cost. We selected the option "Prevent mid-polytomy" to ensure that no coevolutionary event was involved in the (very short) branches created to resolve polytomies.

ParaFit is not dependent on fully resolved phylogenies and uses matrices of phylogenetic distances for both hosts and parasites [12]. Three types of information are used to describe the situation in matrix form: a matrix of phylogenetic distances among parasites, a matrix of phylogenetic distances among hosts, and a matrix of the observed host-parasite associations. All of the combined consensus data of parasitoids and hosts were used to statistically assess the global fit between trees and the significance of the contribution of each individual link between taxa to this global congruence. Tests of significance were performed using 999 permutations.

\section{Availability of supporting data}

GenBank accession numbers are provided in Additional file 1: Table S1 and Additional file 2: Table S2). The sequence alignments for tree construction have been deposited in the TreeBASE with accession URL (http:// purl.org/phylo/treebase/phylows/study/TB2:S15010).

\section{Additional files}

Additional file 1: Table S1. List of scale insect samples used for molecular work. (Collectors' names are abbreviated as follows: $F P Z=$ Fang-Ping Zhang; $G H H=$ Guo-Hua Huang; $H B L=$ Hai-Bin Li; $H L L=$ Hong-Liang Li; $H L=H u L i ; J D=J u n$ Deng; JQW = Jian-Qin Wu; KJW = Kai-Ju Wei; NN = Nan Nan; QS = Qiang Shen; SAW = San-An Wu; $\mathrm{SBH}=$ Shao-Bin Huang; $X \mathrm{XHY}=\mathrm{Xiu}-\mathrm{Hao}$ Yang; $X \mathrm{~L}=X \mathrm{Xian} \mathrm{Li} ; \mathrm{YJZ}=$ Ying-Jie Zhang; $Y W=$ Ying Wang; $Y Z Z$ = Yan-Zhou Zhang; $Y Q X=$ Yu-Qiang $X i)$.

Additional file 2: Table S2. List of parasitoid samples used for molecular work. Specimens of parasitoids used in the study. (Collectors' names are abbreviated as follows: JD = Jun Deng; $J \mathrm{~L}=$ John LaSalle; DYH = Dun-Yuan Huang; HLL = Hong-Liang Li; JL = Jie Li; SAW = San-An Wu; YZZ = Yan-Zhou Zhang).

\section{Competing interests}

The authors declare that they have no competing interests.

\section{Authors' contributions}

$J D, F Y$ and $Y Z Z$ assembled all of the sequences. JD, FY, HBL, MG, YD and $Y Z Z$ performed data analyses. JD, MG, YD, SAW and YZZ wrote the manuscript. All of the authors read and approved the final manuscript.

\section{Acknowledgments}

We are grateful to two anonymous reviewers for helpful comments, to Bodil Cass for kindly revising the English language, and to the following people who helped us to collect Ceroplastes samples: Guo-Hua Huang (Hunan
Agricultural University, Changsha), Shao-Bin Huang (Guangdong Forestry Vocational Technology College, Guangzhou), Jian-qin Wu (The Administrative Bureau of Tianbaoyan National Nature

Reserve of Yong'an, Yong'an), Kai-Ju Wei (Youxi No.1 Middle School of Fujian Province, Youxi), Hong-Liang Li (Institute for Nutritional Sciences, SIBS, Chinese Academy of Sciences, Shanghai), Hu Li (Guizhou University, Guiyang), Xian Li (Forestry Protection Station of Chengdu, Sichuan), Qiang Shen (Forestry Protection Station of Yuyao, Ningbo), Xiu-Hao Yang (Forestry Protection Station of Guangxi, Nanning), Ying-Jie Zhang (Yunnan Agricultural University, Kunming), Nan Nan and Xu-Bo Wang (Beijing Forestry University, Beijing), Ying Wang (Northeast Forestry University, Harbin). The project was supported by the Natural Science Foundation of China (NSFC grant no. 31272350, 31372151), the Fundamental Research Funds for the Central Universities (BLYJ201305), the Chinese Academy of Sciences (KSCX2-YW-NF-02) and in part by the Department of Science and Technology of China (2012FY111100).

\section{Author details}

${ }^{1}$ Key Laboratory of Zoological Systematics and Evolution, Institute of Zoology, Chinese Academy of Sciences, Beijing 100101, China. ${ }^{2}$ Key Laboratory for Silviculture and Conservation of Ministry of Education, Beijing Forestry University, Beijing 100083, China. ${ }^{3} \mathrm{CNR}$,- Istituto per la Protezione delle Piante, UOS di Portici, Via Università 133, 80055 Portici (NA), Italy. ${ }^{4}$ Department of Entomology, The University of Arizona, 410 Forbes Building, Tucson, AZ 85721, USA. ${ }^{5}$ Sorbonne Universités, UPMC Univ Paris 06, UMR 7232, Integrative Biology of Marine Organisms, Observatoire Océanologique, F-66650 Banyuls/Mer, France. ${ }^{6} \mathrm{CNRS}$, UMR 7232, Integrative Biology of Marine Organisms, Observatoire Océanologique, F-66650 Banyuls/Mer, France.

Received: 25 September 2013 Accepted: 18 December 2013

Published: 23 December 2013

\section{References}

1. Kellogg VL: Distribution and species-forming of ecto-parasites. Am Nat 1913, 47:129-158.

2. Brooks DR: Testing the context and extent of host-parasite coevolution. Syst Biol 1979, 28(3):299-307.

3. Brooks DR: Hennig's parasitological method: A proposed solution. Syst Biol 1981, 30(3):229-249.

4. Brooks DR, Glen DR: Pinworms and primates: a case study in coevolution. Proc Helminthol Soc Washington 1982, 49:76-85.

5. Cressey R, Collette B, Russo J: Copepods and scombrid fishes: A study in hostparasite relationships. National Marine Fisheries Service: Fishery bulletin United States; 1983:81.

6. Hafner MS, Nadler SA: Phylogenetic trees support the coevolution of parasites and their hosts. Nature 1988, 332:258-259.

7. Desdevises Y, Morand S, Jousson O, Legendre P: Coevolution between Lamellodiscus (Monogenea: Diplectanidae) and Sparidae (Teleostei): the study of a complex host-parasite system. Evolution 2002, 56(12):2459-2471.

8. Light JE, Hafner MS: Codivergence in heteromyid rodents (Rodentia: Heteromyidae) and their sucking lice of the genus Fahrenholzia (Phthiraptera: Anoplura). Syst Biol 2008, 57(3):449-465.

9. Page RD: TreeMap 1.0. Division of Environmental and Evolutionary Biology, Institute of Biomedical and Life Sciences. Glasgow, UK: University of Glasgow: 1995.

10. Ronquist F: Reconstructing the history of host-parasite associations using generalised parsimony. Cladistics 1995, 11(1):73-89.

11. Ronquist F: TreeFitter 1.0. Computer program distributed by the author Uppsala: Uppsala University; 2000

12. Legendre $P$, Desdevises $Y$, Bazin E: A statistical test for host-parasite coevolution. Syst Biol 2002, 51(2):217-234.

13. Boeger WA, Kritsky DC: Coevolution of the Monogenoidea (Platyhelminthes) based on a revised hypothesis of parasite phylogeny. Int J Parasitol 1997, 27(12):1495-1511.

14. Paterson AM, Palma RL, Gray RD: How frequently do avian lice miss the boat? Implications for coevolutionary studies. Syst Biol 1999, 48(1):214-223.

15. Johnson KP, Clayton DH: Coevolutionary history of ecological replicates: comparing phylogenies of wing and body lice to Columbiform hosts. In Tangled Trees: phylogeny, cospeciation and coevolution. Chicago: University of Chicago press: Page RDM; 2003:262-286. 
16. Demastes JW, Hafner MS: Cospeciation of pocket gophers (Geomys) and their chewing lice (Geomydoecus). J Mammal 1993, 74(3):521-530.

17. Hafner MS, Sudman PD, Villablanca FX, Spradling TA, Demastes JW, Nadler SA: Disparate rates of molecular evolution in cospeciating hosts and parasites. Science 1994, 265:1087-1090.

18. Hafner MS, Page RD: Molecular phylogenies and host-parasite cospeciation: gophers and lice as a model system. Phil Trans R Soc Lond Ser B 1995, 349(1327):77-83.

19. Paterson AM, Wallis GP, Wallis LJ, Gray RD: Seabird and louse coevolution: Complex histories revealed by $12 \mathrm{~S}$ rRNA sequences and reconciliation analyses. Syst Biol 2000, 49(3):383-399.

20. Banks JC, Paterson AM: Multi-host parasite species in cophylogenetic studies. Int J Parasitol 2005, 35(7):741-746

21. Hughes J, Kennedy M, Johnson KP, Palma RL, Page RD: Multiple cophylogenetic analyses reveal frequent cospeciation between pelecaniform birds and Pectinopygus lice. Syst Biol 2007, 56(2):232-251.

22. Itino T, Davies SJ, Tada H, Hieda Y, Inoguchi M, Itioka T, Yamane S, Inoue T: Cospeciation of ants and plants. Ecol Res 2001, 16(4):787-793.

23. Lopez-Vaamonde C, Rasplus JY, Weiblen GD, Cook JM: Molecular phylogenies of fig wasps: partial cocladogenesis of pollinators and parasites. Mol Phylogenet Evol 2001, 21(1):55-71.

24. Ronquist F, Liljeblad J: Evolution of the gall wasp-host plant association. Evolution 2001, 55(12):2503-2522.

25. Marussich WA, Machado CA: Host-specificity and coevolution among pollinating and nonpollinating new world fig wasps. Mol Ecol 2007, 16(9):1925-1946

26. Holst-Jensen A, Kohn L, Jakobsen K, Schumacher T: Molecular phylogeny and evolution of Monilinia (Sclerotiniaceae) based on coding and noncoding rDNA sequences. Am J Bot 1997, 84(5):686.

27. SImková A, Morand S, Jobet E, Gelnar M, Verneau O: Molecular phylogeny of congeneric monogenean parasites (Dactylogyrus): a case of intrahost speciation. Evolution 2004, 58(5):1001-1018.

28. Huyse T, Volckaert FA: Comparing host and parasite phylogenies: Gyrodactylus flatworms jumping from goby to goby. Syst Biol 2005, 54(5):710-718

29. Jackson AP, Charleston MA: A cophylogenetic perspective of RNA-virus evolution. Mol Biol Evol 2004, 21(1):45-57.

30. Dimcheff DE, Drovetski SV, Krishnan M, Mindell DP: Cospeciation and horizontal transmission of avian sarcoma and leukosis virus gag genes in galliform birds. J Virol 2000, 74(9):3984-3995.

31. Althoff DM: A test of host-associated differentiation across the 'parasite continuum'in the tri-trophic interaction among yuccas, bogus yucca moths, and parasitoids. Mol Ecol 2008, 17(17):3917-3927.

32. Lopez-Vaamonde C, Godfray C, West SA, Hansson C, Cook JM: The evolution of host use and unusual reproductive strategies in Achrysocharoides parasitoid wasps. J Evol Biol 2005, 18:1029-1041.

33. Godfray HCJ: Parasitoids: behavioral and evolutionary ecology. Princeton University Press: Princeton; 1994.

34. Noyes J: Universal chalcidoidea database. In World Wide Web electronic publication; 2013. http://www.nhm.ac.uk/chalcidoids (accessed October 2013).

35. Smith D: Biological control of Ceroplastes rubens Maskell, by the introduced parasitoid Anicetus beneficus Ishii and Yasumatsu. Qld J Agric Anim Sci 1986, 43(2):101-105.

36. Kim H, Moon D, Park J, Lee S, Lippold P, Chang Y: Studies on integrated control of citrus pests. (2) Control of ruby scales (Ceroplastes rubens) on citrus by introduction of a parasitic natural enemy, Anicetus beneficus (Hymenoptera: Encyrtidae). Korean J Plant Protection 1979, 18:107-110.

37. Krull S, Basedow T: Evaluation of the biological control of the pink wax scale Ceroplastes rubens Maskell (Hom., Coccidae) with the introduced parasitoid Anicetus beneficus Ishii \& Yasumatsu (Hym., Encyrtidae) in the Central province of Papua New Guinea. J Appl Entomol 2005, 129(6):323-329.

38. Zhang YZ, Si S, Zheng JT, Li HL, Fang Y, Zhu CD, Vogler AP: DNA barcoding of endoparasitoid wasps in the genus Anicetus reveals high levels of host specificity (Hymenoptera: Encyrtidae). Biol Control 2011, 58(3):182-191.

39. Deng J, Yu F, Zhang TX, Hu HY, Zhu CD, Wu SA, Zhang YZ: DNA barcoding of six Ceroplastes species (Hemiptera: Coccoidea: Coccidae) from China. Mol Ecol Resour 2012, 12(5):791-796.

40. Herre EA: Barcoding helps biodiversity fly. Proc Natl Acad Sci USA 2006, 103(11):3949-3950
41. Bickford D, Lohman DJ, Sodhi NS, Ng PK, Meier R, Winker K, Ingram KK, Das I: Cryptic species as a window on diversity and conservation. Trends Ecol Evol 2007, 22(3):148-155.

42. Smith MA, Wood DM, Janzen DH, Hallwachs W, Hebert PD: DNA barcodes affirm that 16 species of apparently generalist tropical parasitoid flies (Diptera, Tachinidae) are not all generalists. Proc Natl Acad Sci USA 2007, 104(12):4967-4972.

43. Gebiola M, Gómez-Zurita J, Monti M, Navone P, Bernardo U: Integration of molecular, ecological, morphological and endosymbiont data for species delimitation within the Pnigalio soemius complex (Hymenoptera: Eulophidae). Mol Ecol 2012, 21(5):1190-1208.

44. Askew R, Shaw MR: Parasitoid communities: their size, structure and development. In Insect Parasitoids, 13th Symposium of Royal Entomological Society of London. Edited by Waage J, Greathead D. London: now Elsevier: Academic Press; 1986:225-264.

45. Chong JH, Oetting RD: Specificity of Anagyrus sp. nov. nr. sinope and Leptomastix dactylopii for six mealybug species. BioControl 2007, 52(3):289-308

46. Noyes J: Copidosoma truncatellum (Dalman) and C. floridanum (Ashmead)(Hymenoptera, Encyrtidae), two frequently misidentified polyembryonic parasitoids of caterpillars (Lepidoptera). Syst Entomol 1988, 13(2):197-204

47. Zolnerowich G: Systematics of the Copidosomatini: Polyembryonic Parasites (Hymenoptera: Encyrtidae). Texas A \& M University: phD thesis; 1995.

48. Gordh G: Biological investigations on Comperia merceti (Compere), an encyrtid parasite of the cockroach Supella longipalpa (Serville). J Entomol. (A) 1973, 47(2):115-123.

49. Willink E, Moore D: Aspects of the biology of Rastrococcus invadens Williams (Hemiptera: Pseudococcidae), a pest of fruit crops in West Africa, and one of its primary parasitoids, Gyranusoidea tebygi Noyes (Hymenoptera: Encyrtidae). Bull Ent Res 1988, 78:709-715.

50. Narasimham A, Chacko M: Rastrococcus spp.(Hemiptera: Pseudococcidae) and their natural enemies in India as potential biocontrol agents for $R$. invadens Williams. Bull Entomol Res 1988, 78(04):703-708.

51. Chesters D, Wang Y, Yu F, Bai M, Zhang TX, Hu HY, Zhu CD, Zhang YZ: The integrative taxonomic approach reveals host specific species in an encyrtid parasitoid species complex. PLoS ONE 2012, 7(5):e37655.

52. Jiggins FM, von Der Schulenburg JH, Hurst GD, Majerus ME: Recombination confounds interpretations of Wolbachia evolution. Proc Biol Sci 2001, 268:1423-1427.

53. Ronquist F: Phylogenetic approaches in coevolution and biogeography. Zool Scr 1997, 26(4):313-322.

54. Johnson PT, Lunde KB, Thurman EM, Ritchie EG, Wray SN, Sutherland DR, Kapfer JM, Frest TJ, Bowerman J, Blaustein AR: Parasite (Ribeiroia ondatrae) infection linked to amphibian malformations in the western United States. Ecol Monogr 2002, 72(2):151-168

55. Weckstein JD: Biogeography explains cophylogenetic patterns in toucan chewing lice. Syst Biol 2004, 53(1):154-164.

56. Banks J, Palma R, Paterson A: Cophylogenetic relationships between penguins and their chewing lice. J Evol Bio/ 2005, 19(1):156-166.

57. Clark MA, Moran NA, Baumann P, Wernegreen JJ: Cospeciation between bacterial endosymbionts (Buchnera) and a recent radiation of aphids (Uroleucon) and pitfalls of testing for phylogenetic congruence. Evolution 2000, 54(2):517-525

58. Jousselin E, Desdevises Y, Coeur d'Acier A: Fine-scale cospeciation between Brachycaudus and Buchnera aphidicola: bacterial genome helps define species and evolutionary relationships in aphids. Proc $R$ Soc Lond B-Biol Sci 2009, 276(1654):187-196.

59. $\mathrm{Xu} \mathrm{ZH}, \mathrm{He} J \mathrm{H}$ : Two new species of the genus Anicetus from China (Hymenoptera: Encyrtidae). Acta Zootaxonomica Sinica 1997, 1:021.

60. Chantos JM, Vinson SB, Helms KR: Distribution and abundance of parasites of the rhodesgrass mealybug, Antonina graminis: reassessment of a classic example of biological control in the southeastern United States. J Insect Sci 2009, 9(48):1-6.

61. Klassen GJ: Coevolution: a history of the macroevolutionary approach to studying host-parasite associations. J Parasitol 1992, 78(4):573-587.

62. Page RD: Tangled trees: Phylogeny, cospeciation, and coevolution. Chicago: University of Chicago Press; 2003.

63. Subba Rao B, Hayat M: The Chalcidoidea (Insecta: Hymenoptera) of India and the adjacent countries. Part II. A catalogue of Chalcidoidea of India and the adjacent countries. Orient Insects 1986, 20:1-430. 
64. Yang ZX, Ren YS: Studies on the different kinds of parasitic wasp of Ceroplastes rubens Mask. and C. japaonica Green and their killing effect on the pests. South China Fruits 1999, 28:16-18.

65. Noyes JS, Hayat M: Oriental mealybug parasitoids of the Anagyrin (Hymenoptera: Encyrtidae). Wallingford: Cab International; 1994

66. Sato H: Parasitoid complexes of lepidopteran leaf miners on oaks (Quercus dentata and Quercus mongolica) in Hokkaido. Japan. Ecol Res 1990, $5(1): 1-8$

67. Sheehan W, Hawkins BA: Attack strategy as an indicator of host range in metopiine and pimpline ichneumonidae (hymenoptera). Ecol Entomol 1991, 16(1):129-131.

68. Memmott J, Godfray H, Gauld ID: The structure of a tropical hostparasitoid community. J Anim Ecol 1994, 63:521-540.

69. Smith MA, Rodriguez JJ, Whitfield JB, Deans AR, Janzen DH, Hallwachs W Hebert PD: Extreme diversity of tropical parasitoid wasps exposed by iterative integration of natural history, DNA barcoding, morphology, and collections. Proc Natl Acad Sci USA 2008, 105(34):12359-12364.

70. Dyer LA, Singer M, Lill J, Stireman J, Gentry G, Marquis RJ, Ricklefs RE, Greeney HF, Wagner DL, Morais H: Host specificity of Lepidoptera in tropical and temperate forests. Nature 2007, 448(7154):696-699.

71. Thompson JD, Higgins DG, Gibson TJ: CLUSTAL W: improving the sensitivity of progressive multiple sequence alignment through sequence weighting, position-specific gap penalties and weight matrix choice. Nucleic Acids Res 1994, 22(22):4673-4680

72. Hall TA: BioEdit: a user-friendly biological sequence alignment editor and analysis program for Windows 95/98/NT. Nucl Acids Symp Ser 1999, 41:95-98.

73. Farris JS, Kallersjo M, Kluge AG, Bult C: Testing significance of incongruence. Cladistics 1995, 10:315-319.

74. Swofford DL: PAUP*. Phylogenetic Analysis Using Parsimony (*and Other Methods). Version 4. Sunderland, Massachusetts: Sinauer Associates; 2003.

75. Posada D: jModelTest: phylogenetic model averaging. Mol Biol Evol 2008, 25(7):1253-1256

76. Ronquist F, Huelsenbeck JP: MrBayes 3: Bayesian phylogenetic inference under mixed models. Bioinformatics 2003, 19(12):1572-1574.

77. Rambaut A, Drummond AJ: Tracer v. 1.5; 2009. http://tree.bio.ed.ac.uk/ software/tracer/(accessed 14 October 2012)

78. Charleston MA, Robertson DL: Preferential host switching by primate lentiviruses can account for phylogenetic similarity with the primate phylogeny. Syst Biol 2002, 51:528-535.

79. Conow C, Fielder D, Ovadia Y, Libeskind-Hadas R: Jane: a new tool for the cophylogeny reconstruction problem. Algorithms Mol Biol 2010, 5(1):16.

80. Meier-Kolthoff JP, Auch AF, Huson DH, Göker M: CopyCat: cophylogenetic analysis tool. Bioinformatics 2007, 23(7):898-900.

81. Page RD: Parallel phylogenies: reconstructing the history of host-parasite assemblages. Cladistics 1994, 10(2):155-173.

82. Mendlová M, Desdevises Y, Civáňová K, Pariselle A, Šimková A: Monogeneans of West African cichlid fish: evolution and cophylogenetic interactions. PLOS ONE 2012, 7(5):e37268.

doi:10.1186/1471-2148-13-275

Cite this article as: Deng et al:: Cophylogenetic relationships between Anicetus parasitoids (Hymenoptera: Encyrtidae) and their scale insect hosts (Hemiptera: Coccidae). BMC Evolutionary Biology 2013 13:275.

\section{Submit your next manuscript to BioMed Central and take full advantage of:}

- Convenient online submission

- Thorough peer review

- No space constraints or color figure charges

- Immediate publication on acceptance

- Inclusion in PubMed, CAS, Scopus and Google Scholar

- Research which is freely available for redistribution

Submit your manuscript at www.biomedcentral.com/submit
C Biomed Central 